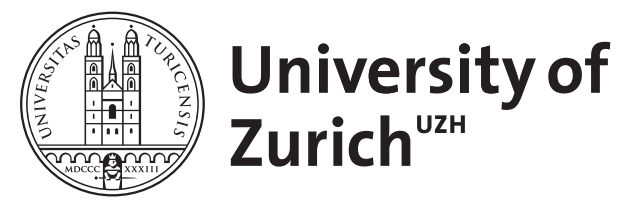

\title{
Nonlinear effects of taxation on growth
}

\author{
Jaimovich, Nir ; Rebelo, Sergio
}

\begin{abstract}
We propose a model consistent with two observations. First, the tax rates adopted by different countries are generally uncorrelated with their growth performance. Second, countries that drastically reduce private incentives to invest severely hurt their growth performance. In our model, the effects of taxation on growth are highly nonlinear. Low tax rates have a very small impact on long-run growth rates. But as tax rates rise, their negative impact on growth rises dramatically. The median voter chooses tax rates that have a small impact on growth prospects, making the relation between tax rates and economic growth difficult to measure empirically.
\end{abstract}

DOI: https://doi.org/10.1086/689607

Posted at the Zurich Open Repository and Archive, University of Zurich ZORA URL: https://doi.org/10.5167/uzh-145763

Journal Article

Published Version

Originally published at:

Jaimovich, Nir; Rebelo, Sergio (2017). Nonlinear effects of taxation on growth. Journal of Political Economy, 125(1):265-291.

DOI: https://doi.org/10.1086/689607 


\title{
Nonlinear Effects of Taxation on Growth
}

\author{
Nir Jaimovich
}

University of Southern California and National Bureau of Economic Research

\section{Sergio Rebelo}

Northwestern University, National Bureau of Economic Research, and Centre for Economic Policy Research

\begin{abstract}
We propose a model consistent with two observations. First, the tax rates adopted by different countries are generally uncorrelated with their growth performance. Second, countries that drastically reduce private incentives to invest severely hurt their growth performance. In our model, the effects of taxation on growth are highly nonlinear. Low tax rates have a very small impact on long-run growth rates. But as tax rates rise, their negative impact on growth rises dramatically. The median voter chooses tax rates that have a small impact on growth prospects, making the relation between tax rates and economic growth difficult to measure empirically.
\end{abstract}

\section{Introduction}

The twentieth century provided two important observations on the determinants of long-run growth. The first observation is that the tax rates adopted by different countries are generally uncorrelated with their growth performance. So, are incentives to invest irrelevant for long-run growth?

We thank the editor, Harald Uhlig, and four anonymous referees for their detailed comments. We also benefited from the comments of Gadi Barlevy, Marco Bassetto, Gideon Bornstein, Martin Eichenbaum, Emmanuel Farhi, and Ben Jones. Arlene Wong provided superb research assistance. Data are provided as supplementary material online.

Electronically published December 19, 2016

[ Journal of Political Economy, 2017, vol. 125, no. 1]

(c) 2017 by The University of Chicago. All rights reserved. 0022-3808/2017/12501-0002\$10.00 
The second observation is that countries that drastically reduce private incentives to innovate and invest severely hurt their growth performance. One salient example is the performance of China between 1949, when communists took over and abolished property rights, and the introduction of reforms by Deng Xiaoping in 1979. Another prominent example is the performance of India under the "permit raj" that lasted from 1947 until the reforms introduced by Rajiv Gandhi and Narasimha Rao in 1984 and 1991, respectively. Interestingly, when these countries gradually restored modest incentives to invest, growth rates increased dramatically. ${ }^{1}$ Here, incentives to invest seem to matter for growth.

To reconcile these two observations, we propose a model in which the effects of taxation on growth are highly nonlinear. Low or moderate tax rates have a small impact on long-run growth rates. But as tax rates and other disincentives to investment rise, their negative impact on growth rises dramatically.

To explain the source of this nonlinearity, it is useful to describe the structure of our model. We combine the growth model proposed by Romer (1990) with the Lucas (1978) model of occupational choice. As in Romer (1990), Grossman and Helpman (1991), and Aghion and Howitt (1992), growth comes from innovation. As in Lucas (1978), the economy is populated by agents who differ in their ability as entrepreneurs/innovators. These agents decide optimally whether to become workers or innovators. Innovators earn profits from their patents, and these profits are subject to capital income taxation.

Motivated by the plethora of evidence on the presence of right skewness in the distribution of patents, scientific paper citations, income, and profits, we assume that the distribution of entrepreneurial ability is skewed. Because of this skewness, most of the innovation in our economy comes from a small number of highly productive innovators, the Bill Gates and Steve Jobs of the model.

Increasing the capital income tax rate reduces incentives to be an entrepreneur and generates exit from the innovation sector. But since the marginal innovator is much less productive than the average innovator, this exit has a small impact on the growth performance of the economy. In other words, the top entrepreneurs in our model are so productive

\footnotetext{
${ }^{1}$ Ahluwalia (2002) discusses the gradualist approach to reform followed by India. McMillan, Whalley, and Zhu (1989) and McMillan and Naughton (1992) discuss the gradual reforms introduced in China and their impact on productivity. In China and India, reforms took place in an environment of political and institutional stability. In contrast, countries from the ex-Soviet bloc often adopted a "big-bang" approach to reform that created substantial political and institutional turmoil that was generally associated with poor economic performance. See McMillan and Naughton (1992) for a comparison of the reforms in China and in the ex-Soviet bloc.
} 
that they are not deterred from innovating by low to moderate tax rates. As a result, there is a range of tax rates that are associated with similar growth outcomes. When taxes and other disincentives to innovate become high, high-quality entrepreneurs exit and the growth engine stalls.

We use our model economy to compute the capital income tax rate chosen by the median voter and by a benevolent planner. We first show that even when the median voter is a worker, he chooses a tax rate on capital income on the flat region of the function relating the tax rate to the growth rate. The reason for this choice is that workers benefit from growth in wages that results from the innovation process and understand that high taxes would severely reduce growth prospects.

Our model implies that punitive tax rates are unlikely to be adopted for extended periods of time in well-functioning democracies or, more generally, in political regimes whose decision makers value growth more than preserving the status quo or maintaining political control. ${ }^{2}$ The optimal choices made by the median voter in our model generate a censored sample in which the observed variation in tax rates has a small impact on growth. So the model is consistent with the absence of a strong correlation between tax rates and growth that we observe in the data. One important implication of the model is that the lack of correlation between taxes and growth is not a global property that holds for all tax rates, but rather an artifact of the endogenous nature of taxation: tax rates that are highly detrimental to the growth process are generally not implemented.

We relate our model to the recent work of Diamond and Saez (2011), who argue that the optimal marginal income tax rate for high-income individuals is 73 percent. We argue that the Diamond-Saez calculation suffers from an important shortcoming: it considers only the static effect of taxation on current tax revenue. Implicitly, this calculation ignores dynamic effects, that is, changes in the growth rate resulting from changes in tax rates. In our model these dynamic effects are small and can be safely ignored when tax rates are low. But it is exactly when tax rates are high, in the range recommended by Diamond and Saez, that these dynamic effects become important.

There are three models consistent with our observation that tax rates are uncorrelated with long-run growth rates: the neoclassical growth model, the Lucas (1988) model, and the Jones (1999) model. In all three models, capital income taxes or other disincentives to investment do not affect the steady-state growth rate. In the neoclassical model, this rate is

${ }^{2}$ The Swedish experience in the 1970s illustrates the impact of public discourse on tax policy. Astrid Lindgren, a successful writer of children's books, published a satirical story about the adverse incentive effects of the punishingly high tax rates levied by Sweden. Her story sparked a public debate that is generally credited with leading to the first electoral defeat of the Social Democratic Party in 40 years and to the reform of the tax code. 
determined by the pace of exogenous technical progress. ${ }^{3}$ In the Lucas model, the engine of growth is the accumulation of human capital. The costs (forgone wages) and benefits (higher future wages) of this accumulation are affected by income taxes in the same proportion. As a result, the growth rate is independent of the income tax rate. ${ }^{4}$ In the semi-endogenous growth model proposed by Jones, the externalities from the innovation process are not strong enough to make growth sustainable. Sustained growth is feasible only when the population grows, and the steady-state growth rate is proportional to the growth rate of population. So taxes influence growth only through their effect on the determinants of population growth. ${ }^{5}$

These models in our view have two shortcomings. First, they are inconsistent with the observation that modest improvements in the incentives to invest, in economies with high disincentives to invest, can produce large growth effects. Second, they imply that long-run growth rates remain constant even when tax rates approach 100 percent.

The paper is organized as follows. In Section II, we review and update the evidence on the empirical correlation between tax rates and growth rates. In Section III, we present our model. In Section IV, we discuss the model's implications for the effects of taxes on growth. In Section V, we analyze the capital income tax rates that the median voter and benevolent social planner would choose. We also discuss the implications of our model for the optimal income tax calculations proposed by Diamond and Saez (2011). Section VI presents conclusions.

\section{Empirical Evidence on Taxation and Growth}

In this section, we briefly review and update the evidence on the correlation between taxation and growth. We discuss evidence both from crosscountry studies and from US time-series analyses.

Cross-country studies.-Easterly and Rebelo (1993) study a cross section of 125 countries for the period 1970-88. Their main finding is that the correlation between various tax rate measures and growth performance

\footnotetext{
${ }^{3}$ In the neoclassical model, taxes can affect growth through transition dynamics. However, versions of the neoclassical model in which these dynamics are important tend to imply that the real interest rate takes implausibly high values. See King and Rebelo (1993) for a discussion.

${ }^{4}$ Stokey and Rebelo (1995) and Mendoza, Milesi-Ferretti, and Asea (1997) discuss variants of the Lucas (1988) model that, for certain parameter configurations, produce a small impact of taxes on long-run growth. These variants include models in which labor supply is endogenous and physical capital is an input to human capital accumulation.

5 Arnold (1998) incorporates human capital accumulation into a Jones (1999) style growth model. The resulting model generates sustained growth in the absence of population growth. Since human capital accumulation is the growth engine of the economy, Arnold's model inherits the properties of the Lucas model in terms of the effects of taxation on growth.
} 
is surprisingly fragile. They show that, while it is possible to select specifications for which taxes are negatively correlated with growth, this correlation is not robust to the inclusion of other controls or to changes in the sample composition.

Mendoza, Razin, and Tesar (1994) find no correlation between tax rates and growth rates in their study of panel data for 18 OECD countries. Similarly, Piketty, Saez, and Stantcheva (2014) find no correlation between growth rates and the changes in marginal income tax rates that have been implemented in OECD countries since 1975.

US time-series analyses.- Stokey and Rebelo (1995) argue that it is hard to detect a negative growth impact of the rise in income tax rates implemented in the United States after World War II. Before the Sixteenth Amendment was approved in 1913, the US Constitution severely restricted the ability of the federal government to levy income taxes. Even after the approval of the Sixteenth Amendment, federal income tax revenue remained low, representing less than 2 percent of gross domestic product (GDP) between 1913 and 1940. Federal income tax revenue as a percentage of GDP rose to 15 percent by the early 1940s. Despite this increase, Stokey and Rebelo find that the average US growth rates before and after World War II are not statistically different. These results were anticipated by Harberger (1964), who observed that US growth rates have been invariant to changes in the tax structure. ${ }^{6}$

Jones (1995) makes the more general point that changes in policy variables tend to be permanent, but growth rates tend to be stationary. In related work, Easterly et al. (1993) show that persistence across decades is low for growth rates but high for policy variables. This finding suggests that caution is needed in attributing high growth rates to good policies, such as low tax rates.

In recent work, Romer and Romer (2010, 2014) use the "narrative record" on the motivation of tax policy changes in the postwar period to identify changes that are exogenous, in the sense that they are not a response to the growth prospects of the economy. Their paper focuses on the short-run effect of taxes on output. They find that, in the postwar period, a tax increase of 1 percent of GDP implies a 3 percent fall in output. Importantly, the authors assume in their empirical work that permanent changes in taxes affect output only temporarily and have no impact on the long-run growth rate of the economy. ${ }^{7}$

\footnotetext{
${ }^{6}$ We cannot, of course, rule out the possibility that, by coincidence, other forces offset exactly the effects of the tax hikes implemented in the postwar period, leaving the growth rate unchanged.

7 See Mertens and Ravn (2014) for additional evidence on the short-run effect of taxation based on Romer and Romer (2010) shocks, as well as a discussion of the related literature.
} 
TABLE 1

Cross-Section and Panel Regressions

\begin{tabular}{lccccc}
\hline \hline & \multicolumn{2}{c}{ Cross-SECTION REgRESSION } & & \multicolumn{2}{c}{ PANEL REgRESSION } \\
\cline { 2 - 3 } \cline { 5 - 6 } & $(1)$ & $(2)$ & & $(3)$ & $(4)$ \\
\hline Labor income tax & .80 & .44 & & .15 & -.05 \\
& $(1.55)$ & $(2.30)$ & & $(.06)$ & $(.09)$ \\
Capital income tax & -1.90 & 3.44 & & -.09 & -.06 \\
& $(2.93)$ & $(3.74)$ & & $(.03)$ & $(.03)$ \\
Controls & No & Yes & & No & Yes \\
$R^{2}$ & .04 & .56 & & .72 & .82 \\
Fixed effects & & & & Yes & Yes \\
Time effects & 17 & & & Yes & Yes \\
Observations & & 17 & & 78 & 71 \\
\hline
\end{tabular}

Source.-Barro-Lee data set, Bureau of Labor Statistics, Mendoza et al. (1994), OECD, Penn World Table, Piketty et al. (2014), and the World Bank.

Note.-Date ranges: 1981-2010 for the cross-sectional regressions and 1965-2010 for the panel regressions. Countries in the sample are Australia, Austria, Belgium, Canada, Denmark, Finland, France, Germany, Greece, Ireland, Italy, Netherlands, New Zealand, Norway, Portugal, Spain, Sweden, Switzerland, the United Kingdom, and the United States. Dependent variable is the growth rate of real, per capita GDP.

Revisiting the correlation between taxation and growth.-To revisit and update the empirical work on taxation and growth, we use the method proposed by Mendoza et al. (1994) to construct measures of tax rates on capital and labor income for OECD countries for the period 1965-2010.

The first two columns of table 1 report results for cross-sectional regressions. The dependent variable is the average annual growth rate of real per capita GDP. The independent variables are our labor and capital tax rate measures. As column 1 shows, neither labor nor capital income taxes have a statistically significant impact on growth. Column 2 includes controls commonly used in the growth literature (see, e.g., Barro 2012). ${ }^{8}$ Here, too, the tax variables are statistically insignificant.

The second two columns of table 1 show the results for panel regressions using 5-year growth rates and 5-year averages of the independent variables. All regressions have time and country fixed effects. Column 1 shows that the coefficients on both tax variables are statistically significant. However, the sign of the labor income tax rate is positive. Once we include controls (col. 4), the coefficients on labor and capital taxes become insignificant. $^{9}$

\footnotetext{
${ }^{8}$ These variables are the logarithm of lagged per capita GDP, 1/life expectancy at birth, the logarithm of fertility, the investment share in GDP, male and female school years, the government consumption share in GDP, the openness ratio, and the inflation rate.

${ }^{9}$ One concern with these regressions is that changes in tax rates might be driven by the economy's growth prospects. In the Appendix, we explore two approaches to address this endogeneity problem.
} 
We interpret the weight of the evidence gathered so far and our updated results as suggesting that there is no strong association between the tax rates adopted by different countries and their growth performance. This body of evidence is consistent with the possibility that taxes might have important level effects or create large deadweight losses. Higher tax rates might, for example, induce agents to work less, as emphasized by Prescott (2004), or to reallocate effort from market activities toward home production, as emphasized by Sandmo (1990). But the evidence is inconsistent with the implication, shared by many endogenous growth models, that the observed changes in capital and labor taxes have large growth effects. ${ }^{10}$

\section{Model}

We consider a Romer (1990) style model in which growth is driven by innovation that expands the variety of intermediate inputs. Agents choose whether to be workers or entrepreneurs, as in Lucas (1978). We focus our analysis on the effect of capital income taxes on the growth rate of the economy.

Importantly, we assume that agents have different entrepreneurial ability and that this ability follows a Pareto distribution. As we discuss below, this assumption is consistent with evidence that the right tail of the US income distribution is well described by the Pareto distribution (see, e.g., Diamond and Saez 2011). It is also consistent with the presence of right skewness in the cross-sectional distribution of profits from innovation, returns to entrepreneurship, and research productivity. ${ }^{11}$ Our assumption that ability is a key driver of skewness in economic performance is motivated by the work of Keane and Wolpin (1997) and Huggett, Ventura, and Yaron (2011), who find that differences in individual ability are a key source of heterogeneity in economic outcomes. ${ }^{12}$

${ }^{10}$ See Barro (1990), Jones and Manuelli (1990), Rebelo (1991), and Stokey and Rebelo (1995) for examples of models that share this implication.

${ }^{11}$ Moskowitz and Vissing-Jorgensen (2002) document the presence of skewness in the returns to entrepreneurial activity. Scherer (1998) and Grabowski (2002) show that a small number of firms account for a disproportionate fraction of the profits from innovation. Bertran (2003), Harhoff, Scherer, and Vopel (2003), Hall, Jaffe, and Trajtenberg (2005), and Silverberg and Verspagen (2007) show that the distribution of patent values and patent citations is highly skewed. Hall et al. show that almost half of all patents receive zero or one citation and less than 0.1 percent of total patents receive more than 100 cites. Lotka (1926) and Cox and Chung (1991) show that the distribution of scientific publications per author is skewed. Redner (1998) finds similar results for the distribution of citations to scientific papers.

12 Recent papers that consider entrepreneurial ability as a major source of heterogeneity include Buera, Kaboski, and Shin (2011) and Midrigan and Xu (2014). 


\section{A. Production}

Final-good producers.-Final-good producers operate a constant-returnsto-scale production function that combines labor $(L)$ with a continuum of measure $n$ of intermediate goods $\left(x_{i}\right)$ :

$$
Y=L^{\alpha} \int_{0}^{n} x_{i}^{1-\alpha} d i
$$

These final-good producers maximize after-tax profits, which are given by

$$
\pi_{f}=\left(L^{\alpha} \int_{0}^{n} x_{i}^{1-\alpha} d i-\int_{0}^{n} p_{i} x_{i} d i-w L\right)(1-\tau),
$$

where $p_{i}$ is the price of intermediate good $i, w$ is the wage rate, and $\tau$ is the capital income tax rate. Both $p_{i}$ and $w$ are denominated in units of the final good. The first-order conditions for this problem are

$$
\begin{gathered}
p_{i}=(1-\alpha) L^{\alpha} x_{i}^{-\alpha}, \\
w=\alpha L^{\alpha-1} n x_{i}^{1-\alpha} .
\end{gathered}
$$

The value of $\pi^{f}$ is zero in equilibrium. For convenience, we normalize the number of final-goods producers to one.

Intermediate good producers/innovators. - Innovators own permanent patents on the production of intermediate goods. Each unit of the intermediate good, $x_{i}$, is produced with $\eta$ units of the final good. The after-tax profit flow, $\pi_{i}$, generated by each new good is given by

$$
\pi_{i}=\left(p_{i}-\eta\right) x_{i}(1-\tau)
$$

Since all producers choose the same price and quantity, we eliminate the subscript $i$ in what follows. Equations (1) and (3) imply that the optimal price and quantity produced by the innovator are

$$
p=\frac{\eta}{1-\alpha}, \quad x=L\left[\frac{(1-\alpha)^{2}}{\eta}\right]^{1 / \alpha} .
$$

The maximal after-tax profit per patent is given by

$$
\pi=\alpha(1-\alpha)^{(2-\alpha) / \alpha} \eta^{-(1-\alpha) / \alpha} L(1-\tau) .
$$

When we optimize the use of intermediate goods in the production of final goods, we obtain a reduced-form production function that is linear in labor. This result, together with the fact that $p$ is constant, implies that 
the wage rate does not depend on $L$. This property greatly simplifies our analysis. Equations (2) and (4) imply that the equilibrium wage rate equals

$$
w_{t}=\alpha n_{t}\left[\frac{(1-\alpha)^{2}}{\eta}\right]^{(1-\alpha) / \alpha} .
$$

For future reference, we note that this equation implies that the wage rate grows at the same rate as $n_{t}$.

\section{B. Government}

The government rebates tax revenue back to agents in a lump-sum manner. Profits gross of taxes are $\left(n_{t} \pi+\pi^{f}\right) /(1-\tau)$. Tax revenue is given by $\tau\left(n_{t} \pi+\pi^{f}\right) /(1-\tau)$. The budget constraint of the government is

$$
T_{t}=\tau \frac{n_{t} \pi+\pi^{f}}{1-\tau}
$$

where $T_{t}$ denotes lump-sum transfers to the agents in the economy.

\section{The Agent's Problem}

The economy is populated by $H$ infinitely lived agents with identical preferences. Agents differ in their entrepreneurial ability, $a$, which follows a cumulative distribution $\Gamma(a)$. To simplify, we assume that individuals with identical ability have the same initial stock of patents and that all agents have zero initial bondholdings. Under these assumptions, the only source of heterogeneity in the economy is the agent's ability.

The utility of an agent with entrepreneurial ability $a, U(a)$, is given by

$$
U(a)=\int_{0}^{\infty} e^{-\rho t} \frac{C_{t}(a)^{1-\sigma}-1}{1-\sigma} d t,
$$

where $C_{t}(a)$ denotes the agent's consumption.

In each period, agents choose whether to work in the final-goods sector and receive the real wage rate, $w_{t}$, or become innovators. An agent with ability $a$ who becomes an entrepreneur invents $\delta a n_{t}$ new goods and obtains a permanent patent on these inventions. ${ }^{13}$

The budget constraint of an agent with ability $a$ is given by

$$
\dot{b}_{t}(a)=r_{t} b_{t}(a)+w_{t} l_{t}(a)+m_{t}(a) \pi_{t}+\pi_{t}^{f} / H-C_{t}(a)+T_{t} / H,
$$

\footnotetext{
${ }^{13}$ We describe in the Appendix an alternative decentralization in which R\&D firms hire innovators in competitive labor markets. The resulting allocations are identical to those in this model.
} 
and

$$
\lim _{t \rightarrow \infty} e^{-\int_{0}^{t} r_{s} d s} b_{t}(a)=0,
$$

where $b_{t}(a)$ denotes the agent's bondholdings and $r_{t}$ the real interest rate.

The variable $l_{t}(a)$ is equal to one if the agent chooses to be a worker in period $t$ and zero otherwise. The variable $m_{t}(a)$ denotes the number of patents owned by an agent with entrepreneurial ability $a$ at time $t$. The law of motion for $m_{t}(a)$ is given by

$$
\dot{m}_{t}(a)=\delta a n_{t}\left[1-l_{t}(a)\right] .
$$

This equation implies that workers receive no new patents, while innovators increase in the stock of patents they hold. As is common in this class of models, there is an externality in the sense that, the larger the value of $n_{t}$, the easier it is to invent new goods. This externality is essential to make sustained growth feasible.

The model generates surprisingly complex borrowing and lending dynamics, which we describe in the Appendix. ${ }^{14}$ But since preferences are consistent with Gorman aggregation, the growth rate of the economy is independent of these borrowing and lending dynamics.

Occupational choice and equilibrium.-We show in the Appendix that the equilibrium of this economy is characterized by a threshold rule. Agents with ability $a \geq a^{*}$ always work as entrepreneurs, while the rest always work in the final-goods sector. So the number of workers in the final-good sector is given by

$$
L=H \Gamma\left(a^{*}\right)
$$

and the growth rate and real interest rate are constant. Thus, the patent's value $V$ is

$$
V=\frac{\pi}{r} .
$$

The threshold ability $a^{*}$ that makes agents indifferent between being a worker and being an entrepreneur is given by ${ }^{15}$

$$
a^{*} \delta n_{t} \frac{\pi}{r}=w_{t} .
$$

\footnotetext{
14 These dynamics arise because, depending on the initial patent holdings and occupational choices, some agents have incomes growing faster or slower than the aggregate economy's growth rate. In the limit, income growth for all agents converges to the growth rate of the economy.

${ }_{15}$ There is evidence that income prospects and taxation influence career choices. For example, Philippon and Reshef (2012) show that, when finance was heavily regulated,
} 
The number of varieties in the economy, $n_{t}$, evolves according to

$$
\dot{n}_{t}=\delta H n_{t} \int_{a^{*}}^{\infty} a \Gamma(d a) .
$$

We show in the Appendix that the growth rate of the economy, $g$, coincides with the growth rate of $n_{t}$,

$$
g=\delta H \int_{a^{*}}^{\infty} a \Gamma(d a) .
$$

Since all agents face the same real interest rate, their consumption grows at the same rate, which coincides with the growth rate of the economy, $g$. The first-order conditions for the consumer problem imply

$$
r=\rho+\sigma g .
$$

Combining equations (5), (6), (10), (11), (12), and (13), we obtain the following equation, which determines $a^{*}$ :

$$
\delta H(1-\alpha) a^{*} \Gamma\left(a^{*}\right)(1-\tau)=\rho+\sigma \delta H \int_{a^{*}}^{\infty} a \Gamma(d a) .
$$

Once we obtain the value of $a^{*}$, we can compute the growth rate of the economy using equation (12).

\section{The Effect of Taxes on Growth}

In order to study the effect of taxes on growth, we need to specify the distribution of entrepreneurial ability, $\Gamma(a)$. Our choice is guided by the work of Diamond and Saez (2011), which shows that the right tail of the US income distribution follows a Pareto distribution. Since entrepreneurial income is proportional to ability, our model is consistent with the evidence provided by Diamond and Saez.

Given this distributional assumption, the growth rate of the economy is given by

$$
g=\delta H \frac{k}{k-1} \underline{a}^{k}\left(a^{*}\right)^{1-k},
$$

where $k$ is the shape parameter, $\underline{a}$ is the lower bound of the Pareto distribution, and $a^{*}$ satisfies (14), which in turn can be written as

profits and labor compensation were low. As a result, high-skill individuals did not work in the financial industry. Deregulation led to higher profits and wages, attracting high-skill individuals to finance. Cullen and Gordon (2007) use US individual tax return data to show that differences in tax rates on business vs. wage income have large effects on the choice to become an entrepreneur. 


$$
(1-\alpha) a^{*}\left[1-\left(\frac{a}{a^{*}}\right)^{k}\right](1-\tau)=\sigma\left[\frac{k}{k-1} \underline{a}^{k}\left(a^{*}\right)^{1-k}\right]+\frac{\rho}{\delta H} .
$$

From these last two equations it follows that the effect of a tax change on the growth rate of the economy is given by

$$
\frac{d g}{d \tau}=\frac{-(\rho+\sigma g)}{1-\tau}\left[\frac{1}{\sigma+(1-\tau)(1-\alpha) \theta}\right],
$$

where $\theta$ is

$$
\theta=1+\frac{1}{k}\left[\left(\frac{a^{*}}{\underline{a}}\right)^{k}-1\right]
$$

Comparing a heterogeneous- and homogeneous-ability economy.-In order to isolate the role of heterogeneity in ability in our model, it is useful to compare an economy with heterogeneous ability with one in which ability is homogeneous ( $a=1$ for all agents). In the homogeneous-ability economy, all agents are indifferent in equilibrium between being workers and being entrepreneurs, so the free-entry condition into the entrepreneurial sector is

$$
\frac{\delta n_{t} \pi}{r}=w_{t}
$$

and the growth rate of the economy is given by

$$
g=\frac{\delta H(1-\alpha)(1-\tau)-\rho}{(1-\alpha)(1-\tau)+\sigma},
$$

implying that the effect of a tax change on the growth rate of the economy is given by

$$
\frac{d g}{d \tau}=\frac{-(\rho+\sigma g)}{1-\tau}\left[\frac{1}{\sigma+(1-\tau)(1-\alpha)}\right]
$$

Consider two economies, one with heterogeneous ability and the other with homogeneous ability. To simplify the comparison, suppose that the two economies have the same structural parameters, $\alpha$ and $\rho$, and the same tax rate, $\tau$. Moreover, the size of the population in each economy is such that they both grow at the same rate $g$.

Comparing equations (17) and (19), we find that the difference in the impact of taxation on growth on the two economies results from $\theta$. When $k$ is finite, the value of $a^{*}$ is greater than $\underline{a}$ since, otherwise, there would 
be no workers or final-goods production, and patents would have no value. Since $a^{*}>\underline{a}$, the value of $\theta$ is greater than one. This property implies that the impact of taxation on growth is always smaller in the heterogeneousability model than in the homogeneous-ability model.

As we discuss in the introduction, the intuition for this result is that in the heterogeneous-ability economy, the marginal innovator is much less productive than the average innovator. So the exit of the marginal entrepreneurs in response to a tax rise has a smaller growth effect than in the homogeneous-ability economy, where the marginal innovator is as productive as the average innovator.

Numerical example.-We use a numerical example to illustrate the effects of changes in the capital income tax rate in economies with homogeneous and heterogeneous ability. The following parameterization is shared by both economies. We set the labor share in the production of final goods to 60 percent $(\alpha=0.60)$. We assume that $\sigma=2$ and we choose $\rho=0.01$, so that the annual real interest rate in an economy with no growth is 1 percent. Without loss of generality, we normalize $\delta$ and $\eta$ to one. Finally, in both the homogeneous and heterogeneous cases, we choose the value of $H$ so that, when $\tau=0.3$, the growth rate of the economy is 2 percent per year. This value of $\tau$ corresponds to the average capital income tax rate in the United States, computed as the tax revenue divided by the base. We normalize the value of $\underline{a}$ to one and choose $k=1.5$. This choice of $k$ implies that the right tail of the income distribution implied by the model is the same as that estimated by Diamond and Saez (2011) for the US economy.

The first panel of figure 1 shows the effect of changes in $\tau$ on the growth rate of the two economies. In the homogeneous-ability model, the growth rate of the economy is approximately linear in $\tau$. The growth rate ranges from 2.9 percent when $\tau=0$ to zero when $\tau=0.87$. Doubling the capital income tax rate from 30 to 60 percent halves the growth rate from 2 percent to 1 percent. Higher taxes reduce the incentives to innovation, reducing the number of entrepreneurs. Since all agents in the economy are equally good at being entrepreneurs, this reduction has a large impact on the rate of growth.

In the heterogeneous-ability model, the growth rate is a nonlinear function of the tax rate. The growth rate ranges from 2.2 percent when $\tau=0$ to zero when $\tau=1$. Doubling the tax rate from 30 to 60 percent reduces the growth rate from 2 to 1.65 percent. This reduction is much smaller than that implied by the homogeneous-ability model (from 2 to 1 percent). The impact of taxation is highly nonlinear in the heterogeneousability economy: increasing $\tau$ from 60 to 79 percent reduces the growth rate by as much as doubling $\tau$ from 30 to 60 percent.

The second panel of figure 1 depicts the fraction of entrepreneurs in the population for different values of $\tau$. In the homogeneous-ability model, 


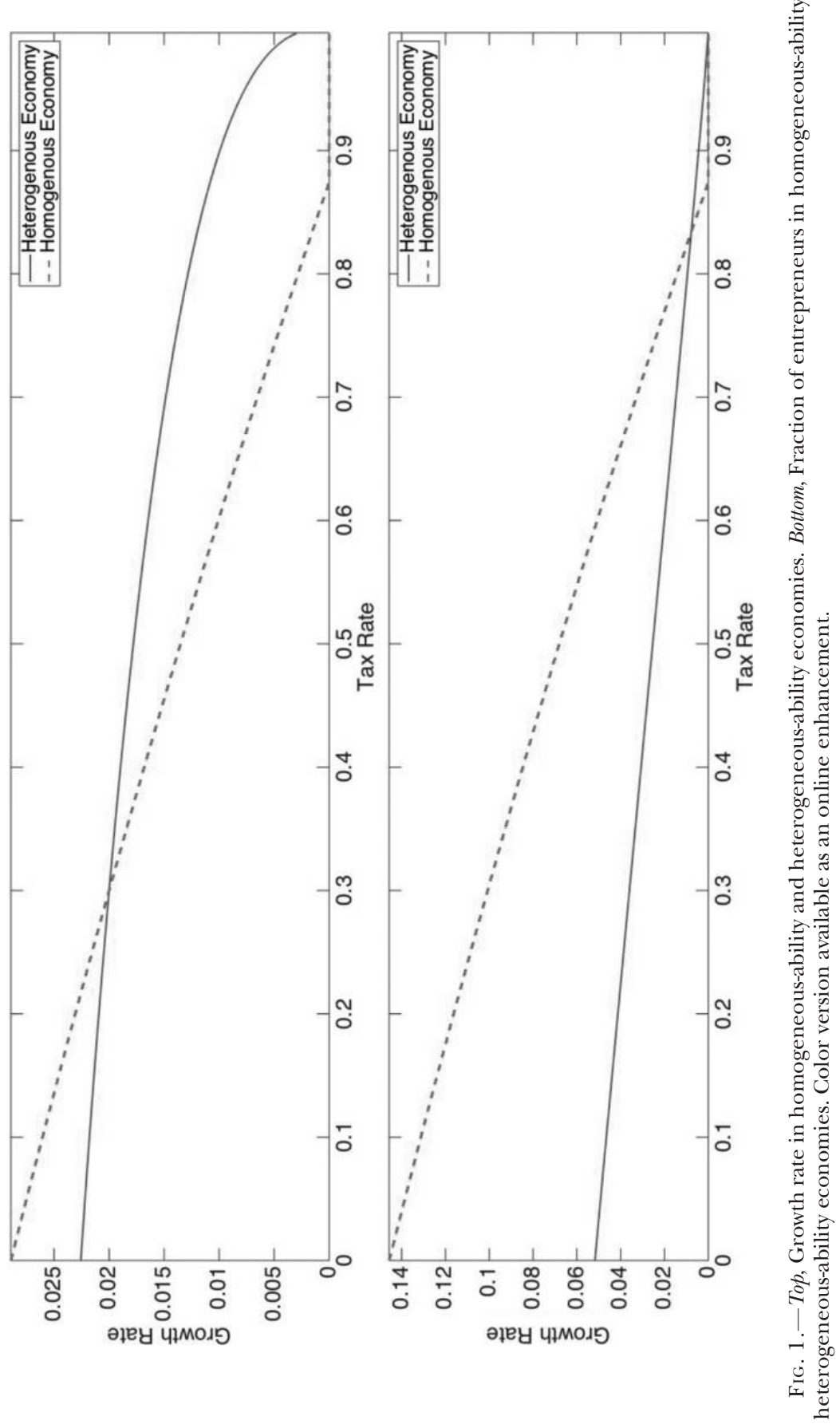

This content downloaded from 130.060.065.097 on January 17, 2018 05:53:51 AM All use subject to University of Chicago Press Terms and Conditions (http://www.journals.uchicago.edu/t-and-c). 
this fraction ranges from 15 percent when $\tau=0$ to zero when $\tau=0.87$. The strong, negative effect of taxes on the number of entrepreneurs is at the core of the homogeneous-agents model's large impact of taxation on growth. In contrast, in the heterogeneous-ability model the fraction of agents who choose to be entrepreneurs ranges from 5.2 percent when $\tau=$ 0 to zero when $\tau=1$. As $\tau$ rises, the number of entrepreneurs declines roughly linearly. But the impact on growth is highly nonlinear, because the ability of the entrepreneurs who exit rises with $\tau$.

\section{The Median Voter and the Social Planner}

In this section, we analyze the capital income tax rates that the median voter and a benevolent social planner would choose for our economy. We conclude this section by relating our findings to the recent work of Diamond and Saez (2011) on the optimal income tax rate for highincome individuals.

\section{A. Median Voter}

We analyze an economy in which the median voter is a worker and workers own no patents at time 0 . This case provides an upper bound on the tax rate chosen by the median voter for two reasons. First, if workers held some patents, they would have less of an incentive to tax capital income. Second, if the median worker was an entrepreneur, he would choose a lower tax rate than a worker, since he receives capital income. A median voter who is an entrepreneur might choose a positive capital income tax rate in order to redistribute income from high-ability to low-ability entrepreneurs.

A worker who is the median voter faces the following trade-off. On the one hand, higher capital income taxes result in higher tax revenue and higher lump-sum transfers in the short run, which benefits workers. On the other hand, higher taxes lead to lower growth in wages in the long run, which hurts workers.

Computing lifetime utility.- Since the consumption of both workers and entrepreneurs grows at a constant rate, we can rewrite lifetime utility, defined in equation (7), as

$$
U=\frac{C_{0}^{1-\sigma}}{1-\sigma} \int_{0}^{\infty} \exp \{[-\rho+(1-\sigma) g] t\} d t .
$$

Assuming that $(1-\sigma) g<\rho$, so that lifetime utility is finite, the value of $U$ is given by

$$
U=\frac{C_{0}^{1-\sigma}}{\rho(1-\sigma)-(1-\sigma)^{2} g} .
$$


As we show in the Appendix, the time 0 consumption of workers is given by

$$
C_{0}=w_{0}+\frac{\tau}{1-\tau} \frac{\pi}{H} n_{0}+\frac{r-g}{r} \pi m_{0}(a), \quad a<a^{*} .
$$

The trade-off faced by the median voter is clear from equations (20) and (21). A higher tax rate benefits workers since it increases the lump-sum transfer they receive from the government (the term $[\tau /(1-\tau)](\pi / H) n_{0}$ in eq. [21]). At the same time, a higher tax rate reduces the growth rate and lowers utility by reducing the denominator in equation (20).

Median voter's preferred tax rate.-The tax rate that maximizes the utility of the median voter for the parameters considered in Section III is 35 percent. We find this result interesting for two reasons. First, this tax rate is very close to the average capital income tax rate, computed as the tax revenue divided by the base, which is roughly 30 percent. Second, the tax rate chosen by the median voter suggests that democracies are unlikely to choose tax rates that are very detrimental to growth prospects. When $\tau$ is equal to 35 percent, the economy grows at an annual rate of 1.95 percent. Reducing the capital income tax rate to zero would increase the growth rate only to 2.25 percent.

The fact that the median voter avoids implementing tax rates that lead to poor growth prospects has important implications for the samples used to study the empirical relation between taxation and growth. These samples are censored in the sense that they generally do not contain the full range of values of $\tau$. Instead, they contain values of $\tau$ on the flat region of the function relating the tax rate to the growth rate, making the relation between taxation and growth hard to detect.

Figure 2 shows the ratio of the initial consumption that would make the median voter indifferent between an arbitrary tax rate $\tau$ and the consumption at the tax rate that maximizes his welfare. This figure illustrates that the effects of taxation on welfare are highly nonlinear, with high rates of taxes being associated with low levels of welfare.

\section{B. Social Planner}

We now consider a social planner who chooses the tax rate to maximize a weighted average of the utility of workers and entrepreneurs:

$$
\max _{\tau} \bar{U}=\int_{\underline{a}}^{\infty} \int_{0}^{\infty}\left\{e^{-\rho t} \frac{\left[C_{t}(a)\right]^{1-\sigma}-1}{1-\sigma} d t\right\} \Gamma(d a) .
$$

Recall that consumption of both workers and entrepreneurs grows at rate $g$. The time 0 consumption of workers is given by equation (21). As we 


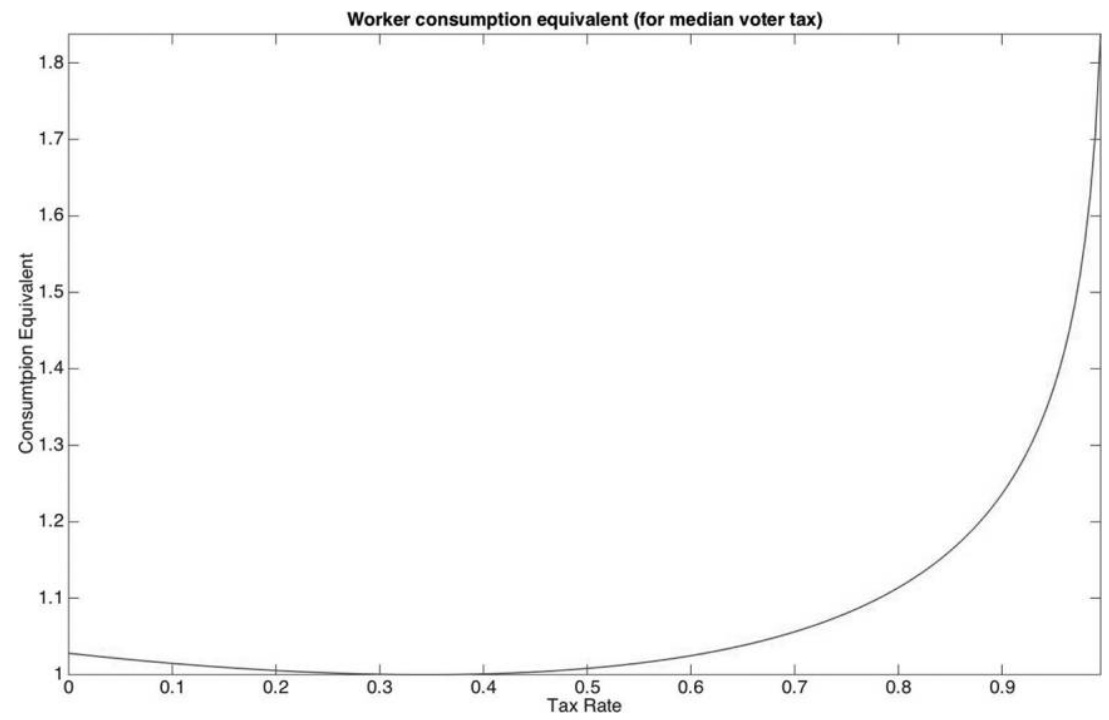

FIG. 2.-Worker consumption equivalent (for median voter tax). Color version available as an online enhancement.

show in the Appendix, the time 0 consumption of entrepreneurs is given by

$$
C_{0}=\pi n_{0}\left[\frac{r-g}{r} \frac{m_{0}(a)}{n_{0}}+\frac{\delta a}{r}+\frac{\tau}{1-\tau} \frac{1}{H}\right], \quad a \geq a^{*} .
$$

For the parameters considered in Section III, the value of $\tau$ that maximizes $\bar{U}$ is 31 percent. We choose the initial distribution of patents so that the social planner has a strong redistribution motive. As in the case of the median voter, we assume that workers do not own any initial patents. In addition, we distribute initial patents equally among the top 1 percent of entrepreneurs ranked by ability. The tax rate chosen by the social planner is basically identical if the initial patents are distributed equally among the top 2 or 3 percent of entrepreneurs ranked by ability.

Since the planner places a positive weight on the welfare of the entrepreneurs, he always chooses a lower tax rate than the worker. The tax rate selected by the social planner is remarkably close to the US capital income tax rate.

\section{Relation to the Modern Public Finance Literature}

The tax rates chosen by the median voter and the social planner in our model are much lower than the optimal tax rates advocated in the modern public finance literature. For example, Diamond and Saez (2011) ar- 
gue that the optimal income tax rate for high-income individuals is 73 percent. This high optimal tax rate results from the fact that highincome individuals have a low elasticity of taxable income with respect to the tax rate.

The Diamond-Saez calculation suffers from an important shortcoming. It considers only the static effect of taxation on current tax revenue. It ignores dynamic effects by implicitly assuming that the growth rate of the economy is invariant with respect to the tax rate. In our model, these dynamic effects are indeed small and can be safely ignored when tax rates are low. But it is exactly when tax rates become high, in the range recommended by Diamond and Saez (2011), that these dynamic effects become significant. ${ }^{16}$

To see this problem, suppose that the government adopts very high tax rates. The static effects of this action are positive for the workers: their wage remains the same and they see a rise in the lump-sum transfers they receive from the government. But the dynamic effects can be disastrous for workers' welfare, since higher taxes lead to a fall in the growth rate of wages. We can use our model to illustrate how misleading the focus on the static effects of taxation can be. Total pretax income in the economy is given by

$$
w_{t} H \Gamma\left(a^{*}\right)+n_{t} \frac{\pi_{t}}{1-\tau} .
$$

An increase in $\tau$ leads to a rise in pretax income. To see this result, note that the derivative of pretax income with respect to $\tau$ is given by

$$
w_{t} H \Gamma^{\prime}\left(a^{*}\right) \frac{d a^{*}}{d \tau}+n_{t} \frac{d\left[\pi_{t} /(1-\tau)\right]}{d \tau}>0 .
$$

This expression reflects the fact that the wage rate is solely a function of $n_{t}$ (see eq. [2]). Since $n_{t}$ is fixed in the short run, $w_{t}$ is not affected by an increase in $\tau$.

As the tax rate rises, the ability threshold also rises $\left(d a^{*} / d \tau>0\right)$, and some entrepreneurs become workers. So the first term in equation (23) is positive. The second term is also positive because a rise in the number of workers leads to a rise in pretax profits (see eq. [5]).

Since the short-run response of pretax income to the tax rate is positive, the tax rate that maximizes short-run tax revenue is 100 percent! A

\footnotetext{
${ }^{16}$ Scheuer (2014) discusses another shortcoming of the Diamond-Saez calculation: it implicitly assumes that tax-driven changes in the labor supply of high-income individuals do not affect the productivity of other agents in the economy. Scheuer illustrates this issue in a model in which the labor supplies of entrepreneurs and workers are complements, so reductions in the entrepreneurial labor supply lead to a decline in the productivity of workers. Our model embodies a natural source of complementarity between entrepreneurs and workers.
} 
planner who considers only the static effects of taxation would choose a high tax rate in order to redistribute income from the entrepreneurs to the workers in order to equalize their marginal utility. But this choice would be misguided since it ignores the impact of taxation on growth, which is a key driver of welfare.

\section{Conclusion}

In this paper, we propose a model in which the effects of taxation on growth are highly nonlinear. Taxes have a small impact on long-run growth when taxes rates and other disincentives to investment are low or moderate. But as tax rates rise, the marginal impact of taxation on growth also rises. This nonlinearity is generated by heterogeneity in entrepreneurial ability. In a low-tax economy, the ability of the marginal entrepreneur is relatively low. So increasing the tax rate leads to the exit of low-ability entrepreneurs and to a small decline in the growth rate. In a high-tax economy the ability of the marginal entrepreneur is relatively high. So increasing the tax rate leads to the exit of high-ability entrepreneurs and a large decline in the growth rate.

\section{Appendix}

\section{A. Endogeneity of Changes in Tax Rates}

One concern with the regressions reported in table 1 is that changes in tax rates might be driven by the economy's growth prospects. We explore two approaches to address this endogeneity problem. The first approach is to instrument for tax rates with the lagged debt-GDP ratio. This approach is motivated by the observation that tax rate increases often result from the need to service the public debt. For example, the tax hikes implemented by many countries after World War II were not a reaction to their growth prospects. Instead, they resulted from the need to service the debt accumulated during the war years. We report the results from using this approach in table A1. ${ }^{17}$ In all cases, we find that the tax coefficients are insignificant.

In our second approach, we separate increases in tax rates from decreases in tax rates. The motivation for this approach is as follows. It is easy to find instances in which policy makers reduce tax rates to improve poor growth prospects. But it is much harder to find instances in which policy makers decide to raise taxes because growth prospects are too bright. So tax increases are likely to be more exogenous to growth prospects than tax decreases. Table A2 reports results for regressions of the change in the growth rate on increases and decreases in tax rates. Columns 1 and 2 show results without and with controls, respectively. In both cases, the coefficients on tax variables are statistically insignificant.

${ }^{17}$ Since we have only one instrument, the tax variables are included in the regression one at a time. 
TABLE A1

Panel Regressions

\begin{tabular}{lcc}
\hline \hline & \multicolumn{2}{c}{ Regression } \\
\cline { 2 - 3 } & $(1)$ & $(2)$ \\
\hline Labor income tax & -.26 & \\
Capital income tax & $(.45)$ & -.14 \\
& & $(.25)$ \\
Controls & Yes & Yes \\
$R^{2}$ & .04 & .13 \\
Fixed effects & Yes & Yes \\
Time effects & Yes & Yes \\
Instrument & Lagged debt/GDP & Lagged debt/GDP \\
Observations & 70 & 70 \\
\hline
\end{tabular}

NotE.-Dependent variable is the growth rate of real, per capita GDP.

\section{B. Solving the Agent's Problem}

We solve the agent's problem in two steps. First, we maximize the agent's wealth. Second, we choose the optimal consumption path given the maximal level of wealth. Integrating equation (8), we obtain

$$
\begin{gathered}
\int_{0}^{\infty} e^{-\int_{0}^{s} r_{j} d j}\left[w_{s} l_{s}(a)+m_{s}(a) \pi_{s}+\pi_{s}^{f} / H+T_{t}\right] d s \\
=\int_{0}^{\infty} e^{-\int_{0}^{s} r_{j} d j}\left[C_{s}(a)\right] d s,
\end{gathered}
$$

where the left-hand side is the wealth of the agent and the right-hand side is the

TABLE A2

PANEL Regressions

\begin{tabular}{lcc}
\hline \hline & \multicolumn{2}{c}{ REGRESSION } \\
\cline { 2 - 3 } & $(1)$ & $(2)$ \\
\hline Increase in labor income tax & .12 & .18 \\
& $(.24)$ & $(.27)$ \\
Increase in capital income tax & -.08 & -.12 \\
& $(.08)$ & $(.09)$ \\
Decrease in labor income tax & .08 & .23 \\
& $(.26)$ & $(.23)$ \\
Decrease in capital income tax & -.25 & -.19 \\
& $(.20)$ & $(.24)$ \\
Controls & No & Yes \\
$R^{2}$ & .69 & .78 \\
Fixed effects & Yes & Yes \\
Time effects & Yes & Yes \\
Observations & 63 & 59 \\
\hline
\end{tabular}

Note.-Dependent variable is the change in the growth rate of real, per capita GDP. 
present value of the agent's consumption. The wealth maximization problem can then be written as

$$
\max \int_{0}^{\infty} e^{-\int_{0}^{s} r_{j} d j}\left[w_{s} l_{s}(a)+m_{s}(a) \pi_{s}+\pi_{s}^{f} / H+T_{t}\right] d s,
$$

subject to equation (9). The Hamiltonian for this problem is

$$
\mathcal{H}=w_{t} l_{t}(a)+m_{t}(a) \pi_{t}+\pi_{t}^{f} / H+T_{t}+V_{t}(a) \delta a n_{t}\left[1-l_{t}(a)\right],
$$

where $V_{t}(a)$, the Lagrange multiplier associated with the law of motion for $m_{t}(a)$, is the value of a patent. We proceed by analyzing the three first-order conditions of the problem.

The first-order condition with respect to $m_{t}(a)$ is

$$
\dot{V}_{t}(a)=r_{t} V_{t}(a)-\pi_{t} .
$$

Solving this differential equation, we obtain

$$
V_{t}=\int_{t}^{\infty} \pi_{j} e^{-\int_{t}^{j} r_{s} d s} d j
$$

where we omit the subscript $a$ because the value of $V_{t}$ is the same for all agents. Equation (A2) implies that the value of a patent for a new good is the discounted value of the profit flow associated with the patent.

The first-order condition with respect to $l_{t}(a)$ implies that there is a threshold ability, $a^{*}$, that makes agents indifferent between being a worker and being an entrepreneur:

$$
a^{*} \delta n_{t} V_{t}=w_{t} .
$$

Agents with ability greater (lower) than $a^{*}$ choose to become entrepreneurs (workers).

Finally, we note that the first-order condition for the consumer problem implies

$$
\frac{\dot{C}_{t}(a)}{C_{t}(a)}=\frac{r_{t}-\rho}{\sigma} .
$$

Since all agents face the same real interest rate, their consumption grows at the same rate. We denote this growth rate by $g$.

\section{Consumption and Bondholdings}

Worker's consumption.-Consider an agent who is a worker, so $l_{t}(a)=1$. The worker's lifetime budget constraint is given by

$$
\int_{0}^{\infty} e^{-r t}\left[w_{0} e^{g t}+m_{0}(a) \pi+T_{t} / H\right] d t=\int_{0}^{\infty} e^{-r t}\left[C_{0}(a) e^{g t}\right] d t
$$


Recall that $\pi_{t}^{f}=0$ and $\pi_{t}$ is constant. The lump-sum transfers received by the worker are

$$
\frac{T_{t}}{H}=\frac{\tau}{1-\tau} \frac{\pi}{H} n_{0} e^{g t}
$$

Integrating equation (A5), we obtain the following equation for consumption at time 0:

$$
C_{0}(a)=w_{0}+\frac{\tau}{1-\tau} \frac{\pi}{H} n_{0}+\frac{r-g}{r} \pi m_{0}(a), \quad a<a^{*} .
$$

Since consumption grows at rate $g$, consumption at time $t$ is given by

$$
C_{t}(a)=w_{t}+\frac{\tau}{1-\tau} \frac{\pi}{H} n_{t}+\frac{r-g}{r} \pi m_{0}(a) e^{g t}, \quad a<a^{*} .
$$

Entrepreneur's consumption.-Recall that the law of motion for the patents of an entrepreneur with ability $a$ is

$$
\dot{m}_{t}(a)=\delta a n_{t}=\delta a n_{0} e^{g t}, \quad a \geq a^{*} .
$$

Integrating this equation, we obtain

$$
m_{t}(a)=m_{0}(a)+\frac{\delta a n_{0}}{g}\left(e^{g t}-1\right), \quad a \geq a^{*} .
$$

The growth rate of $m_{t}(a)$ is given by

$$
\frac{\dot{m}_{t}(a)}{m_{t}(a)}=\frac{g}{1+e^{-g t}\left[g m_{0}(a) /\left(\delta a n_{0}\right)-1\right]}, \quad a \geq a^{*} .
$$

This entrepreneur's lifetime budget constraint is given by

$$
\int_{0}^{\infty} e^{-r t}\left[m_{t}(a) \pi+T_{t} / H\right] d t=\int_{0}^{\infty} e^{-r t}\left[C_{0}^{e}(a) e^{g t}\right] d t, \quad a \geq a^{*} .
$$

Using equations (A6), (A9), and (A10), we obtain

$$
C_{0}^{e}(a)=\pi\left[\left(\frac{r-g}{r}\right) m_{0}(a)+\frac{\delta a n_{0}}{r}+\frac{1}{H} \frac{\tau n_{0}}{1-\tau}\right], \quad a \geq a^{*} .
$$

Since consumption grows at rate $g$, consumption at time $t$ is given by

$$
\begin{array}{ll}
C_{t}^{e}(a) & =\pi n_{t}\left[\left(\frac{r-g}{r}\right) \frac{m_{0}(a)}{n_{0}}+\frac{\delta a}{r}+\frac{1}{H} \frac{\tau}{1-\tau}\right], \quad a \geq a^{*}, \\
\dot{b}_{t}(a) & =\pi\left[m_{0}(a)+\frac{\delta a}{g}\left(n_{t}-n_{0}\right)\right]-\pi\left[m_{0}(a) e^{g t}+\frac{\delta a n_{t}}{r}\right], \quad a \geq a^{*} .
\end{array}
$$

Borrowing and lending between agents.-The evolution of bondholdings for an entrepreneur of ability $a$ is given by

$$
\dot{b}_{t}^{e}(a)=r b_{t}^{e}(a)+m_{t}(a) \pi-C_{t}^{e}(a)+T_{t} / H .
$$


Using equation (A9) and the expression for consumption, we can rewrite the evolution of the bondholding as

$$
\begin{aligned}
\dot{b}_{t}^{e}(a)= & r b_{t}^{e}(a)+\pi\left[m_{0}(a)-n_{0} \frac{\delta a}{g}\right] \\
& +\pi\left[n_{0} \delta a\left(\frac{1}{g}-\frac{1}{r}\right)-m_{0}(a) \frac{r-g}{r}\right] e^{g t} .
\end{aligned}
$$

Integrating this equation, we obtain

$$
b_{t}^{e}(a)=\pi\left[m_{0}(a)-\frac{\delta a n_{0}}{g}\right] \frac{e^{g t}-1}{r} .
$$

This equation implies that entrepreneurs whose initial stock of patents is greater (lower) than $n_{0} \delta a / g$ are lenders (borrowers). Entrepreneurs with an initial stock of patents equal to $n_{0} \delta a / g$ have zero bondholdings. To understand these patterns, it is useful to integrate equation (9):

$$
m_{t}(a)=m_{0}(a)+\frac{\delta a n_{0}}{g}\left(e^{g t}-1\right), \quad a \geq a^{*} .
$$

Recall that the entrepreneur's time $t$ income is $m_{t}(a) \pi$, where $\pi$ is constant (see eq. [5]). When $m_{0}(a)=n_{0} \delta a / g$, entrepreneurial income grows at the same rate as consumption, so the entrepreneur does not need to use bond markets to make his consumption stream consistent with his income stream. When $m_{0}<$ $n_{0} \delta a / g$, entrepreneurial income grows faster than $g$, and so entrepreneurs borrow against future income. When $m_{0}>n_{0} \delta a / g$, entrepreneurial income grows slower than $g$, and so entrepreneurs lend in order to consume more than their income in the future.

With the appropriate modification of the problem, we can also obtain the bondholding of a worker (recall that the stock of patents held by workers is constant over time):

$$
b_{t}(a)=m_{0}(a) \pi \frac{e^{g t}-1}{r}, \quad a<a^{*} .
$$

When the initial stock of patents held by the workers is zero, their bondholdings are zero. When this stock is positive, workers' income grows slower than $g$, so workers lend in order to consume more than their labor income in the future.

\section{Alternative Decentralization}

Consider the following alternative decentralization of the equilibrium. Competitive R\&D firms choose the fraction $\omega(a)$ of workers with ability $a$ in order to invent new goods and sell the resulting patents. The problem for these firms is

$$
\max \dot{m}_{t} V-\int_{\underline{a}}^{\infty} W_{t}(a) \omega(a) d a
$$


subject to

$$
\dot{m}_{t}=\int_{\underline{a}}^{\infty} \delta n_{t} a \omega(a) d a .
$$

The first-order condition for this problem is

$$
\delta n_{t} a V=W_{t}(a)
$$

Since all workers can earn $w_{t}$ in the labor market, the only workers who seek employment as entrepreneurs are those with $a \geq a^{*}$, where $a^{*}$ is given by

$$
W_{t}\left(a^{*}\right)=w_{t}
$$

which we can rewrite as

$$
\delta n_{t} a^{*} V=w_{t} .
$$

Since $V=\pi / r$, this equation is equivalent to equation (A3).

\section{E. Transitional Dynamics}

1. Homogeneous-Ability Model

We first show that the homogeneous-ability model has no transitional dynamics:

$$
\pi=\alpha(1-\alpha)^{(2-\alpha) / \alpha} \eta^{-(1-\alpha) / \alpha} L(1-\tau) .
$$

Equations (2) and (4) imply that the equilibrium wage rate is given by

$$
w_{t}=\alpha n_{t}\left[\frac{(1-\alpha)^{2}}{\eta}\right]^{(1-\alpha) / \alpha} .
$$

Recall that the value of a patent for a new good is

$$
V_{t}=\int_{t}^{\infty} \pi_{j} e^{-\int_{t}^{j} r_{s} d s} d j
$$

When there is an interior solution for the number of entrepreneurs, we have

$$
\delta n_{t} V_{t}=w_{t} .
$$

Using equation (A14) to compute $\dot{V}_{t}$, we obtain

$$
\dot{V}_{t}=\frac{d}{d t} \int_{t}^{\infty} \pi_{j} e^{-\int_{t}^{j} r_{s} d s} d j
$$

Define

$$
f(t, j)=e^{-\int_{t}^{j} r_{s} d s} \pi_{j}
$$

Using Leibnitz's rule we obtain 


$$
\dot{V}_{t}=\frac{d}{d t} \int_{t}^{\infty} f(t, j) d j=-\pi_{t}+r_{t} V_{t}
$$

Equation (A13) implies that $w_{t} / n_{t}$ is constant. This property, together with equation (A15), implies that the value of the firm, $V_{t}$, is also constant. Given that $\dot{V}_{t}=$ 0 , equation (A16) implies

$$
V_{t}=\frac{\pi_{t}}{r_{t}}
$$

Replacing $\pi_{t}$ and $r_{t}$ in equation (A17) for $V_{t}$,

$$
V_{t}=\frac{\alpha(1-\alpha)^{(2-\alpha) / \alpha} \eta^{-(1-\alpha) / \alpha} L_{t}(1-\tau)}{\sigma \delta\left(H-L_{t}\right)+\rho} .
$$

Rearranging,

$$
\alpha(1-\alpha)^{(2-\alpha) / \alpha} \eta^{-(1-\alpha) / \alpha} L_{t}(1-\tau)=V\left[\sigma \delta\left(H-L_{t}\right)+\rho\right] .
$$

Differentiating with respect to time, using the fact that $\dot{V}_{t}=0$, we have

$$
\alpha(1-\alpha)^{(2-\alpha) / \alpha} \eta^{-(1-\alpha) / \alpha} \dot{L}_{t}(1-\tau)=-\dot{L}_{t} V \sigma \delta .
$$

This equation implies that $\dot{L}_{t}=0$, so $L_{t}$ is constant. This property implies that $\pi_{t}$ is constant (eq. [A13]). Equation (A17) implies that $r_{t}$ is constant. In sum, the model has no transition dynamics.

\section{Heterogeneous-Ability Model}

The free-entry condition in the heterogeneous-ability model is

$$
n \delta a_{t}^{*} V_{t}=w_{t} .
$$

Since $w_{t} / n_{t}$ is constant, we have

$$
\frac{\dot{a}_{t}^{*}}{a_{t}^{*}}+\frac{\dot{V}_{t}}{V_{t}}=0 .
$$

Conjecture that $\dot{a}^{*}=0$, so $a_{t}^{*}=a^{*}$. The free-entry condition is

$$
V_{t}=\frac{w_{t}}{n \delta a^{*}} .
$$

We can now proceed as in the homogeneous-agent model and show that the real interest rate and the growth rate are constant and that all equations are satisfied, so that a constant value of $a_{t}^{*}$ is indeed a solution.

\section{References}

Aghion, Philippe, and Peter Howitt. 1992. "A Model of Growth through Creative Destruction.” Econometrica 60 (2): 323-52. 
Ahluwalia, Montek S. 2002. "Economic Reforms in India since 1991: Has Gradualism Worked?” J. Econ. Perspectives 16 (Summer): 67-88.

Arnold, Lutz. 1998. "Growth, Welfare, and Trade in an Integrated Model of Human Capital Accumulation and Research.” J. Macroeconomics 20:81-105.

Barro, Robert J. 1990. "Government Spending in a Simple Model of Endogenous Growth.” J.P.E. 98, no. 5, pt. 2 (October): S103-S125.

. 2012. "Convergence and Modernization Revisited." Working Paper no. 18295, NBER, Cambridge, MA.

Bertran, Fernando Leiva. 2003. "Pricing Patents through Citations." Manuscript, Univ. Rochester.

Buera, Francisco, Joe Kaboski, and Yongs Shin. 2011. "Finance and Development: A Tale of Two Sectors.” A.E.R. 101:1964-2002.

Cox, Raymond, and Kee H. Chung. 1991. "Patterns of Research Output and Author Concentration in the Economics Literature." Rev. Econ. and Statis. 73: $740-47$.

Cullen, Julie Berry, and Roger H. Gordon. 2007. "Taxes and Entrepreneurial Risk-Taking: Theory and Evidence for the U.S." J. Public Econ. 91:1479-1505.

Diamond, Peter, and Emmanuel Saez. 2011. "The Case for a Progressive Tax: From Basic Research to Policy Recommendations." J. Econ. Perspectives 25 (4): 165-90.

Easterly, William, Michael Kremer, Lant Pritchett, and Lawrence Summers. 1993. "Good Policy or Good Luck? Country Growth Performance and Temporary Shocks." J. Monetary Econ. 32:459-84.

Easterly, William, and Sergio Rebelo. 1993. "Fiscal Policy and Economic Growth: An Empirical Investigation.” J. Monetary Econ. 32 (December): 417-58.

Grabowski, Henry. 2002. "Patents and New Product Development in the Pharmaceutical and Biotechnology Industries." In Proceedings of the 2002 Conference on Exploring the Economics of Biotechnology, edited by John V. Duca and Mine K. Ycel. Dallas: Fed. Reserve Bank.

Grossman, Gene M., and Elhanan Helpman. 1991. "Quality Ladders in the Theory of Growth." Rev. Econ. Studies 58 (1): 43-61.

Hall, Bronwyn H., Adam Jaffe, and Manuel Trajtenberg. 2005. "Market Value and Patent Citations." Rand J. Econ. 36 (Spring): 16-38.

Harberger, Arnold. 1964. "Taxation, Resource Allocation and Welfare." In The Role of Direct and Indirect Taxes in the Federal Reserve System. Princeton, NJ: Princeton Univ. Press (for NBER).

Harhoff, Dietmar, Frederic M. Scherer, and Katrin Vopel. 2003. "Exploring the Tail of Patented Invention Value Distributions." In Economics, Law and Intellectual Property: Seeking Strategies for Research and Teaching in a Developing Field, edited by Ove Granstrand. Boston: Springer.

Huggett, Mark, Gustavo Ventura, and Amir Yaron. 2011. "Sources of Lifetime Inequality." A.E.R. 101 (7): 2923-54.

Jones, Charles I. 1995. "Time Series Tests of Endogenous Growth Models." Q.J.E. 110 (2): 495-525.

- 1999. "Growth: With or Without Scale Effects?" A.E.R. 89:139-44.

Jones, Larry E., and Rodolfo E. Manuelli. 1990. "A Convex Model of Equilibrium Growth: Theory and Policy Implications.” J.P.E. 98, no. 5, pt. 1 (October): 1008-38.

Keane, Michael P., and Kenneth I. Wolpin. 1997. "The Career Decisions of Young Men." J.P.E. 105 (3): 473-522.

King, Robert G., and Sergio Rebelo. 1993. "Transitional Dynamics and Economic Growth in the Neoclassical Model." A.E.R. 83 (4): 908-31.

Lotka, A. J. 1926. "The Frequency Distribution of Scientific Productivity." J. Washington Acad. Sci. 16:317-23. 
Lucas, Robert E., Jr. 1978. "On the Size Distribution of Business Firms.” Bell J. Econ. 9:508-23.

1988. "On the Mechanics of Economic Development." J. Monetary Econ. 22 (1): 3-42.

McMillan, John, and Barry Naughton. 1992. "How to Reform a Planned Economy: Lessons from China." Oxford Rev. Econ. Policy 8 (1): 130-43.

McMillan, John, John Whalley, and Lijing Zhu. 1989. "The Impact of China's Economic Reforms on Agricultural Productivity Growth.” J.P.E. 97 (4): 781-807.

Mendoza, Enrique, Gian Maria Milesi-Ferretti, and Patrick Asea. 1997. "On the Ineffectiveness of Tax Policy in Altering Long-Run Growth: Harberger's Superneutrality Conjecture." J. Public Econ. 66:99-126.

Mendoza, Enrique, Assaf Razin, and Linda Tesar. 1994. "Effective Tax Rates in Macroeconomics: Cross-Country Estimates of Tax Rates on Factor Incomes and Consumption." J. Monetary Econ. 34:297-323.

Mertens, Karel, and Morten Ravn. 2014. "A Reconciliation of SVAR and Narrative Estimates of Tax Multipliers.” J. Monetary Econ. 68:1-19.

Midrigan, Virgiliu, and Daniel Yi Xu. 2014. "Finance and Misallocation: Evidence from Plant-Level Data.” A.E.R. 104 (2): 422-58.

Moskowitz, Tobias J., and Annette Vissing-Jorgensen. 2002. "The Returns to Entrepreneurial Investment: A Private Equity Premium Puzzle?” A.E.R. 92 (September): $745-78$.

Philippon, Thomas, and Ariell Reshef. 2012. "Wages and Human Capital in the US Finance Industry: 1909-2006.” Q.J.E. 127 (4): 1551-1609.

Piketty, Thomas, Emmanuel Saez, and Stefanie Stantcheva. 2014. "Optimal Taxation of Top Labor Incomes: A Tale of Three Elasticities." American Econ. J.: Econ. Policy 6 (1): 230-71.

Prescott, Edward. 2004. "Why Do Americans Work So Much More than Europeans?" Fed. Reserve Bank Minneapolis Q. Rev. 28 (July): 2-13.

Rebelo, Sergio. 1991. "Long-Run Policy Analysis and Long-Run Growth." J.P.E. 99 (June): 500-521.

Redner, S. 1998. "How Popular Is Your Paper? An Empirical Study of the Citation Distribution." European Physics J. B4:131-34.

Romer, Christina D., and David H. Romer. 2010. "The Macroeconomic Effects of Tax Changes: Estimates Based on a New Measure of Fiscal Shocks." A.E.R. 100:763-801.

- 2014. "The Incentive Effects of Marginal Tax Rates: Evidence from the Interwar Era." American Econ. J.: Econ. Policy 6 (3): 242-81.

Romer, Paul M. 1990. "Endogenous Technological Change." J.P.E. 98:71-102.

Sandmo, Agnar. 1990. "Tax Distortions and Household Production." Oxford Econ. Papers 42:78-90.

Scherer, Frederic M. 1998. "The Size Distribution of Profits from Innovation." In "The Economics and Econometrics of Innovation," special issue, Annales d'Économie et de Statistique (49/50): 495-516.

Scheuer, Florian. 2014. "Entrepreneurial Taxation with Endogenous Entry." American Econ. J.: Econ. Policy 6:126-63.

Silverberg, Gerald, and Bart Verspagen. 2007. "The Size Distribution of Innovations Revisited: An Application of Extreme Value Statistics to Citation and Value Measures of Patent Significance.” J. Econometrics 139:318-39.

Stokey, Nancy L., and Sergio Rebelo. 1995. "Growth Effects of Flat-Rate Taxes." J.P.E. 103 (3): 519-50. 